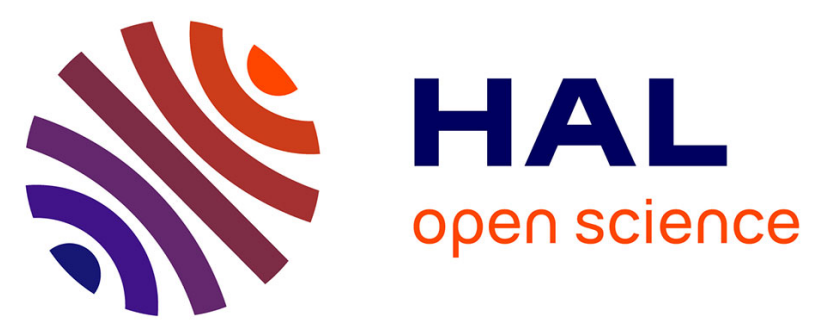

\title{
Policy lensing of future-oriented strategic intelligence: An experiment connecting foresight with decision making contexts
}

Douglas K. R. Robinson, Antoine Schoen, Philippe Larédo, Jordi Molas

Gallart, Philine Warnke, Stefan Kuhlmann, Gonzalo Ordóñez-Matamoros

\section{To cite this version:}

Douglas K. R. Robinson, Antoine Schoen, Philippe Larédo, Jordi Molas Gallart, Philine Warnke, et al.. Policy lensing of future-oriented strategic intelligence: An experiment connecting foresight with decision making contexts. Technological Forecasting and Social Change, 2021, 169, 10.1016/j.techfore.2021.120803 . hal-03232913

\section{HAL Id: hal-03232913 https://hal.science/hal-03232913}

Submitted on 26 Dec 2021

HAL is a multi-disciplinary open access archive for the deposit and dissemination of scientific research documents, whether they are published or not. The documents may come from teaching and research institutions in France or abroad, or from public or private research centers.
L'archive ouverte pluridisciplinaire HAL, est destinée au dépôt et à la diffusion de documents scientifiques de niveau recherche, publiés ou non, émanant des établissements d'enseignement et de recherche français ou étrangers, des laboratoires publics ou privés. 


\title{
Policy lensing of future-oriented strategic intelligence: An experiment connecting foresight with decision making contexts
}

\author{
Douglas K.R. Robinson 1, 2, , Antoine Schoen', Philippe Laredo1, 3, Jordi Molas Gallart 4, \\ Philine Warnke ${ }^{5}$, Stefan Kuhlmann 6 , Gonzalo Ordóñez-Matamoros ${ }^{6,7}$ \\ 1 LISIS - Laboratory for Interdisciplinary studies of Science Innovation and Society, Université Gustave Eiffel - CNRS - INRAE, IFRIS, Champs-sur-Marne, \\ France. \\ 2 Institute for Innovation and Public Purpose (IIPP), UCL, London, UK \\ ${ }^{3}$ Manchester Business School, The University of Manchester, Booth St W, Manchester M15 6PB, UK \\ ${ }^{4}$ INGENIO, CSIC-UPV, Polytechnic University of Valencia, Camí de Vera s/n, 46007 Valencia, Spain \\ ${ }^{5}$ Fraunhofer Institute for Systems and Innovation Research ISI, Breslauer Strasse 48, 76139 Karlsruhe \\ ${ }^{6}$ Science, Technology, and Policy Studies (STəPS), University of Twente, Enschede, the Netherlands \\ ${ }^{7}$ Facultad de Finanzas, Gobierno y Relaciones Internacionales. Universidad Externado de Colombia, Colombia \\ *Email: contact@douglas-robinson.com
}




\section{Highlights}

- The struggle in connecting futures intelligence to policy making can be read as a basic challenge in foresight.

- Policy lenses are proposed to interpret futures intelligence from the perspective of a policy maker.

- Lenses can focus on, for example, priorities such a mission-oriented policies, forms of Europeanisation or the variety of policy formation and implementation spaces

- An experiment is presented in developing and applying tailored lenses for European research and innovation policy. 


\section{Abstract}

The rich and complex outcomes of foresight activities are often difficult to translate into policy relevant intelligence. The struggle in connecting futures intelligence to policy making can be read as a basic challenge in foresight: working on futures intelligence has emerged as a way to improve policy, but once it is delegated to professional foresight practitioners with attendant quality and quality control, however, it also introduces a distance to policy making. Whilst independence and methodological rigour is desirable for high quality futures intelligence, bridging this intelligence with the policy context is essential for its use. Experiencing this challenge during a scenario exercise on the future European research and innovation system, the authors of this paper embarked on an experiment to go beyond evaluating the robustness of the scenarios, produced in a foresight exercise, by developing and applying "policy lenses" to translate the scenarios into policy tailored intelligence. This paper describes the experiment, which saw the development and application of three types of policy lenses: (1) a lens based on the layered processes of European policy making, (2) a lens based on three research and innovation policy priorities and (3) a lens on alternative geopolitical situations of the European continent. The paper describes the logic behind the lenses, the interpretation of the original scenarios when viewed through these lenses, and then concludes by reflecting on how such an experiment could be generalised to other settings of policy-oriented foresight.

Keywords: Policy-lensing, Innovation systems, research systems, scenarios, mission-oriented policy, Europeanisation 


\section{Introduction}

\subsection{Bridging foresight with policy as a basic challenge}

Decision makers are challenged to develop strategies and policies for the future, but often do so in situations of high uncertainty. To be able to manage this challenge, strategic intelligence is required in a variety of forms (Rotolo et al. 2017, Cagnin et al. 2008, Smits et al. 2004). Foresight is a systematic process of developing strategic intelligence, mobilising understandings of the past and structured articulation of potential futures - to aid decision making (EFFLA 2014, Robinson et al 2019).

Foresight practitioners, both in academic and professional spheres, have developed a wealth of tools, techniques and applications of foresight, and scenario building is one of the most widely established methods to create futures intelligence. Foresight scholars refer to scenarios as consistent images of possible futures (Bowman et al 2020, Ringland 2002) and it is argued that rigorously imagining different futures forces us to stretch our mental models and confront our collective and individual clichés, biases and anticipatory assumptions (Miller and Sandford 2019, Miller 2007, Godet 2001). Furthermore, scenario building is expected to enable organisations to generate projects and decisions that are more robust under a variety of alternative futures (van der Heijden 2005, p. 5) but also to better unlock the potential of the present by reaping the potential of the complexity of our surroundings (Bourgeois et al. 2017).

Part of the benefit of scenario development is expected to emerge through the collective process of developing the scenarios themselves, which has been termed a "strategic conversation" (van der Heijden 2005, Bourgeois et al. 2017). Accordingly, in several scenario exercises the development process is deemed as important as the scenarios themselves (van Asselt, et al. 2010 p. 29). Benefits that are mentioned most often include deliberation of expectations, forming of shared language and common ground across diverse actor groups, raising awareness about upcoming challenges (da Costa et al 2008) and opening up of perception filters (Schirrmeister and Warnke 2013) see the special issue of TFSC on the Knowledge Management and Foresight in 2019 and more broadly the journal articles that study the cognitive dimensions of foresight (Boe-Lillegraven and Monterde, 2015, Rhisiart et al. 2015, Bootz, 2010, Glick et al, 2012; Haeffner et al. 2012).

While these benefits may well emerge within the scenario development process ${ }^{1}$ the generation of policy actions from scenarios is less obvious and differs widely for different types of scenarios (van Notten et al. 2003, Elsawah et al. 2020). Scenarios, and other forms of futures intelligence holds particular relevance for policy makers active in research, innovation and technology policy (Van Woensel 2019, Weber \& Schaper-Rinkel 2017). However, the often very rich and complex exploratory scenarios are difficult to translate into policy relevant intelligence (Minkkinen et al. 2019).

Some scenarios already incorporate a certain policy approach and are targeted at specific policy actors and tailored to their perspectives. Often in these cases one scenario describes an optimum strategy and a desired outcome such as the "Flight of the Flamingos" in the famous "Mont Fleur" scenarios on the future of South Africa (van Asselt, et al. 2010 p.30). This type of scenario is often called "normative" and the scenarios can directly be used to discuss strategic options for policy (Menzies et al. 2020).

In many cases, however, scenarios are not targeted at a specific actor or policy interest, but elaborate different possible contexts or environments of the future world and, in some cases, the actions and consequences of particular stakeholders therein. In some of these cases there is no best or worst case scenario, but all scenarios combine different elements into a consistent and coherent representation of the future, that will be perceived to be positive or

1 It is often stressed however that in order to achieve lasting impact the mindset of the scenario building needs to be incorporated into the organization (Ringland 2002, van der Heijden, Pillkahn) 
negative depending on the readers' perspective. ${ }^{2}$ Policy makers, confronted with these rich and "general purpose", scenarios, are challenged to distil and make sense of them, linking to their own policy making context.

The struggle in connecting non-policy-targeted future-oriented strategic intelligence to policy making can be read as a basic challenge in foresight: working on future-oriented strategic intelligence has emerged as a way to improve policy shaping, but once it is delegated to professional foresight analysts with attendant quality and quality control, however, it also introduces a distance to policy making. Whilst independence and methodological rigour is desirable for high quality futures intelligence, bridging this intelligence with the policy context is essential for futures intelligence to be used in decision making.

We experienced this "basic challenge in foresight" during a scenario exercise on the future European Research and Innovation System (the VERA project, see below). As analysts, we wanted to use the developed scenarios as intelligence relevant for policy, particularly research and innovation policy aiming to draw recommendations for those making decisions, particularly at the European level.

The authors of this paper realised that mere evaluation of the robustness of the developed scenarios is not enough to connect the "general-purpose" foresight to policy making worlds. Our hypothesis is that this requires an additional step, dedicated to distilling the scenarios, coming from the VERA project, into policy relevant intelligence. To explore this hypothesis, the authors of this paper decided to experiment with such an "additional step" by putting themselves in the position of a policy shaper and interpreting the "general-purpose" scenarios from a policy shaper perspective, taking into account the policy priorities around research and innovation (the focus of the VERA project), the rooms for manoeuvre of policy shapers (the contexts of decision making and governance of research and innovation) and the broader question of degrees and forms of Europeanisation of the research and innovation system (another focus of the VERA project). ${ }^{3}$

This paper describes and discusses our experiment to do this "additional step" by further articulating the VERA project scenarios through three so-called "policy lenses". As we will describe, for the case of research and innovation policy, such a further articulation builds future research and innovation landscapes that can be compared and contrasted from the perspective of a policy shaper. This allows to better articulate (a) what differs between each scenario and (b) what differs between the scenarios and the present day. In this way, policy lenses connect the scenarios to the present-day policy situation.

The remainder of the paper will describe the logic behind, and application of, the policy lensing approach. Section 2 first presents, in brief, the original "general-purpose" foresight exercise leading to four scenarios. Section 3 will describe how a policy-lensing group was formed and the rationale behind the three policy-lenses that we applied. In addition, we provide a description of the theoretical and empirical basis for each of the three lenses developed and mobilised in our policy lensing experiment. Section 4 presents the results of the lensing by first showing the matrix that was created by the experiment team (which included the authors of this paper) followed by the interpretation of the scenarios after the lensing step. The paper concludes with a reflection on policy lensing technique and its possible further generalisation.

\footnotetext{
2 This type of exploratory context scenario has been widely used to underpin strategic decision making ever since it was introduced by Pierre Whack for Shell in the early 1970s (van der Heijden 2005, p. 3). In these situations, the scenarios create a conceptual wind tunnel where strategies can be tested under various conditions.

3 A "policy shaper" is an actor who both informs and directs policy, in our case this is specific to research and innovation at regional, national and European level. This means that the term "policy shaper" can be read more broadly than "government official" or indeed "public agency" since it can also include, intermediary organisations that influence policy, international organisations such as the OECD that provide policy intelligence that influences policy.
} 


\section{The need for experimenting with new approaches}

The VERA project (Forward Visions on the European Research Area) 4 took scenarios as its central methodology in order to support future oriented strategy building for research and innovation actors in Europe. The objective was to develop contrasting scenarios which would aid the project consortium in exploring the key issues, drivers and interdependencies of future research and innovation landscapes (Miles et al. 2017, Robinson 2009, Van Vliet et al. 2012). The scenarios were developed using the "Three Horizons" futures technique (Sharpe et al. 2016) with some elements of multi-level entanglements (Köhler et al. 2019). For the scenarios developed in VERA, a key factor approach was chosen from the variety of available scenario development methods, and was applied following a common four step approach:
a) The identification and selection of key factors,
b) The development of alternative assumptions for each factor, referred to as "factor projections",
c) The development of different scenarios as consistent combinations of these assumptions, and
d) The writing of scenario essays on this basis.

This process enabled a systematic and transparent scenario development with distinct scenarios of European research and innovation governance and its context. ${ }^{5}$ Workshops were also employed as a tool to develop alternative factor projections making use of stakeholders' knowledge, insights and expertise (van Vliet et al. 2012, p. 755). This allowed the expansion of the set of alternative aspects that would feed into the scenario and further elaborate the interdependencies and tensions between them.

\section{Box 1: Summarising four European research and innovation system scenarios}

\section{Scenario 1: Private Knowledge - Global Markets}

In this scenario, today's European Research Area (ERA) gradually evolves into a Global Innovation Area, where research is mainly legitimized by its contribution to innovativeness, competitiveness and growth. As a result of limited public funds, growing inequalities between Member States and the jostling for political influence within Europe, private actors, mainly firms, dominate the financing of the research landscape and thus the setting of research priorities. The coordination and integration of worldwide research, technological development and innovation are primarily managed by global, vertical networks.

\section{Scenario 2: Societal Challenges - Joint Action}

EU Member States have become increasingly open to collective action to tackle societal challenges such as climate change or health protection. Joint Actions emerge as large programmes with large public investments in R\&D complemented by NGO investment and activities and a greater role for regions. The role of the European institutions becomes increasingly important and this leads to a substantial change in the governance system, with the European Parliament taking a central policy role.

\section{Scenario 3: Solutions apart - Local is Beautiful}

Today's understanding of progress is transformed into a human-centred rationale, where happiness and quality of life are operationalized into new measures of progress. Research and innovation in Europe are transparent and open to individual or societal needs, in particular regarding new ways of living together, health or data privacy, with active citizen participation and close ties with local societal actors around micro/regional level activities addressing local problems.

\footnotetext{
4 https://cordis.europa.eu/project/id/290705

5 The full scenarios, developed in the FP7 funded VERA project, as well as the tools and approaches employed can be found as supplementary material to this publication (as a Data In Brief file) and the full scenarios and construction process can be found at the project archive website: http://eravisions.archiv.zsi.at/page/22/attach/WP3_ERA_Scenario_report_final_28052015.pdf
} 


\section{Scenario 4: Times of Crises - Experts at the Wheel}

Climate catastrophes unfold disruptive forces leading to societal transformation. A new sense of 'deep sustainability' on which all economic, political and societal activities are based requires targeted scientific adaptation solutions. European-level coordination is key in steering research, technological development and (social) innovation towards this goal. Experts in sustainability play key policy roles becoming heavily involved in policy definition and implementation.

The four VERA scenarios, summarised in Box 1, differed from the wind tunnelling type of scenarios (described in footnote 2) in two key respects. Firstly, they are not pure "context scenarios". Rather the behaviour of several key actors' such as European and national level research and innovation policy makers, universities, NGOs, citizens and industry is actually incorporated into the scenarios along with some more factors more external to the research and innovation system such as the global economic situation. This approach is in line with the insight that in the case of policy oriented scenarios the wind tunnelling is less useful as "policy free" scenarios will hardly provide relevant storylines. Secondly, in contrast to scenarios being developed for one particular client, for example the normative scenarios for policy makers mentioned previously, the VERA scenarios are meant to support future oriented strategy building for a wide range of actor groups concerned with research and innovation in Europe and beyond. Each of these actors needs to engage in their own sense making process in order to draw conclusions for their strategy building.

Therefore, there is a need for policy lensing of future-oriented strategic intelligence, like scenarios, where the strategic intelligence is not created or targeted for a policy audience, and requires an additional translational step. This challenge has been recognised elsewhere. For example, Havas et al. 2017 for policies for the next industrial revolution, Weber et al. 2018 regarding parliamentary foresight and technology assessment, Frau 2020 with regards to foresight for and in public policy making. A recent special issue of the journal Futures, focus on how different sociotechnical futures circulate amongst policy actors (and others involved in the governance of innovations), observing a similar challenge with regards to the nature and roles of translating future-oriented strategic intelligence into policy relevant insights (Konrad and Böhle 2019). Of course, this is not only a recent issue, as Da Costa et al 2008 observe, challenges of translating future-oriented strategic intelligence into policy use are abundant.

\section{Developing three policy lenses}

\subsection{Building a policy-lensing experiment focus group}

The policy lensing experiment was initiated as an additional activity of the VERA project after the four scenarios were constructed. After internal reflection within the VERA consortium, a focus group was created comprising academic researchers with expertise in both (a) research and innovation policy studies and (b) foresight techniques. The members of the team were drawn from within the consortium, some of whom had been part of the original scenario development exercise. See Table 1 for a description of the members of the policy lensing focus group.

The aim of this experimental team was to further articulate which policy intelligence was needed to inform on European research, technology, development and innovation (RTDI) policies so that relevant insights from the scenarios could be translated and amplified. Thus, a two-step process was envisaged. First, the construction of policy lenses based on policy needs, which was done in a day-long workshop (Section 3.2). The second step was the process of lensing itself using the different lenses to translate and amplify elements of the four scenarios, this was done in a day-long workshop of all of the policy lensing team and was followed up by online interactions (Section 4). 


\begin{tabular}{|l|l|}
\hline Description & Expertise \\
\hline Research Scientist & $\begin{array}{l}\text { Approximately 15-years' experience in innovation studies, foresight and policy, with } \\
3 \text { years experience in strategic intelligence consultancy }\end{array}$ \\
\hline University Professor / EC Joint Research Centre & $\begin{array}{l}\text { Approximately 20-years' experience in foresight and research and innovation policy. } \\
50 \% \text { Academic 50\% working at the European Commission Joint Research Centre }\end{array}$ \\
\hline University Professor / Civil servant in a Ministry & $\begin{array}{l}\text { Approximately 40-years' experience on research policies, innovation studies, } \\
\text { evaluation and foresight }\end{array}$ \\
\hline University Professor / Civil servant in a Ministry & $\begin{array}{l}\text { Approximately 40-years' experience on research and innovation systems, policy } \\
\text { and strategic intelligence }\end{array}$ \\
\hline University Professor & $\begin{array}{l}\text { Approximately 30-years' experience in evaluation of science, technology and } \\
\text { innovation policies and the use of indicators in evaluation }\end{array}$ \\
\hline University Professor & $\begin{array}{l}\text { Approximately 20-years' experience in global developments in public policy and } \\
\text { evaluation of research and innovation. }\end{array}$ \\
\hline University Professor / EC Joint Research Centre & Approximately 40-years' experience on research policies, evaluation and foresight \\
\hline University Professor / EC Joint Research Centre & $\begin{array}{l}\text { Approximately 20-years' experience in foresight and research and innovation policy. } \\
50 \% \text { Academic 50\% working at the European Commission Joint Research Centre }\end{array}$ \\
\hline
\end{tabular}

Table 1: Description of participants and expertise in the policy lensing team (all but the bottom two experts are authors of this article).

\subsection{Developing relevant lenses}

The goal of the VERA project was to provide relevant strategic intelligence for the future governance and priority-setting of the RTDI system in Europe and for better adapting science, technology and innovation policy to the shifting global environment and upcoming socio-economic challenges. Therefore, relevant policy lenses should help translate the four VERA scenarios into relevant intelligence to advise policy development and implementation related to these goals.

The policy lensing focus group conducted a day-long workshop to construct the policy lenses, building on theoretical insights into the dynamics of RTDI and current policy intelligence needs. The size of the group (8 persons) was conducive to brainstorming techniques and discussions, which allowed for the co-construction of three policy lenses.

The logic therefore was to have a lens that would put the perspective of the policy maker/shaper up front. Such a lens would (a) capture the location of policy development and implementation (particularly for policies targeting research, technology, development and innovation) and (b) reflect the action space (or "room for manoeuvre") of the policy actor. This lens we will describe in Section 3.2.1.

Since the goal of the VERA project was to inform policy on policy actions linked to shifting socio-economic challenges and other RTDI policy priorities, it was decided that a lens capturing the main policy priorities of the day should be developed. This lens we will describe in section 3.2.2.

Finally, since the VERA project was focused on the European RTDI system, it was clear that the nature of "Europe" with regards to RTDI could evolve in different ways. European-level policy would therefore benefit from an understanding of the nature of Europeanisation within the four scenarios. This lens, focusing on degrees and forms of Europeanisation, will be described in section 3.2.3 


\subsubsection{Lens 1: Observing scenarios through the functional layers of research and innovation policy}

A long tradition of the $\mathrm{OECD}^{6}$ (linked to the post WWII construction of 'science and technical policies', later extended to 'research and technology policies, and now to 'innovation policies') separates two universes: resource allocation on the one hand (associated with policy definition) and performance on the other. Barré and colleagues (2013) have proposed a further enlargement considering a functional approach to policy, differentiating orientation, programming, and performance as "macro-functions" in research and innovation policy.

Barré et al. mobilise principal-agent theory and apply it to research and innovation policy. In their perspective, the basic question for research and innovation policy is to understand how non-researchers and non-innovators get researchers and innovators (agents) to do what citizens represented by public authorities (principal) have decided. They observe that the principal in this situation, who disposes resources to agents, may not have the capacities to judge the best means of targeting the resources, lacking capacities, skills and data. They argue that an intermediary "programming" layer, lies between the public authorities that, as principal, defines what needs to be done through strategic orientations, and the researchers and innovators, as agents, perform activities to contribute to these strategic orientations. In such a way, funding agencies, research councils, innovation funds etc. are included as key governance actors in the RTDI system, located in the so-called programming layer.

In the policy lensing focus group, we proposed to adopt this model to describe the research and innovation landscape in Europe as three nested functional layers (see Box 2). For the orientation layer we were interested in how priorities are defined. At the programming layer the focus group articulated four questions that they thought relevant: (a) is there an encompassing European framework programme? ${ }^{7}$ (b) since industries played a strong role in the VERA scenarios, do we see the sectorialisation of research and innovation activities? (c) what are the main modes of EU activities for societal challenges? And since communication was a visible element in the scenarios,(d) what is specific role of communication programmes? At the performance layer, we were interested in two main aspects: (a) the role of firms and (b) the science and technology base (considering the role of Public Research Organisations (PROs) and the orientation of universities).

\section{Box 2: Functional layers}

(1) Orientation functional layer: Involves the definition of policy objectives and the ways in which the policies envisaged will work towards the achievement of such objectives. Activities in this layer are conducted by political authorities, elaborating the governance and budget for RTDI and defining the overarching objectives and rationales to steer the RTDI system.

(2) Programming functional layer: Activities in this layer are conducted by organisations such as funding agencies and other intermediary organisations that mediate between RTDI actors and the state. This layer involves the translation of the objectives stated by the political authorities of orientation layer into specific thematic priorities that direct and shape the allocation of resources to RTDI actors (such as researchers, innovating firms etc.)

(3) Performance functional layer: Activities in this layer are conducted by research and innovation performers (public research organisations, universities, firms, others) and involves the production of knowledge and innovation through the activities of researchers, operation of research infrastructures, management of projects, networks and the diffusion of knowledge.

\footnotetext{
${ }^{6}$ The Organisation for Economic Co-operation and Development.

7 The Framework Programmes for Research and Technological Development, often shortened to "Framework Programmes" are funding programmes managed by the European Commission to support and foster research in the European Research Area (ERA). Starting in 1984, the current Framework Programme (Horizon Europe) runs from 2021 to 2027 and has an approximate budget of $€ 95.5$ billion. https://ec.europa.eu/info/horizon-europe_en
} 


\subsubsection{Lens 2: Observing scenarios through research and innovation policy priorities}

There is a long-standing debate about the role of states and Governments in shaping and directing RTDI systems (Borras and Edler 2020, Mazzucato 2018, Chaminade \& Edquist 2010). In the policy-lensing focus group, these theoretical debates about the role of the state, as well as trends in European policy, where taken into consideration. Three major priorities were identified and agreed to be relevant for the policy lensing of VERA scenarios: (1) Missionoriented research and innovation; shaping and facilitating the European innovation ecosystem (with protection of inventors, protection of users and coping with market failures); and support to the specific (quasi) public good that is science.

1. Mission-oriented research and innovation. In 2017, the Lamy Report proposed that the European Commission take a mission-oriented, impact-focused approach to address global challenges (Lamy, 2017). Whereas societal challenges may be considered as the broader social problem aim or benefit that is being sought (e.g. fighting climate change), missions represent a more narrowly defined set of activities that are supposed to deliver a verifiable result on a planned timescale that can be used to measure progress in overcoming the societal challenge. In the world of policymaking, research and innovation policies targeted at societal grand challenges rather than purely economic growth have been argued to be a new type of policy (Borras and Edler 2020, Schot and Steinmueller 2019). Such policies contribute to facilitating innovation and socio-economic impact in a particular direction towards a desirable transformative change (Gassler et al. 2008, Weber and Rohracher 2012, Mazzucato 2018, Hekkert et al. 2019). Over 40 mission-oriented policies are being experimented with around the globe (Larrue 2021) and Missions are at the heart of the latest European Framework Programme, Horizon Europe., therefore mission-oriented research and innovation is a key policy priority. ${ }^{8}$

2. Facilitating the innovation ecosystem. Invention and new products have been at the core of the 'capitalist revolution', and with it the protection of the inventors. For example, protecting inventors so that they can profit from the fruit of their inventions is written in the US constitution. ${ }^{9}$ Framing market conditions is a central remit of policies, and has been de facto a central element of the Europeanisation of markets (with standards in particular). Thus, a key policy priority for Europe is the support and facilitation of the European innovation ecosystem in a number of ways (a) the protection of inventors, (b) the support of standards and other market infrastructures, (c) public procurement and (d) the ecology of firms and other innovation actors.

3. Support for fundamental and breakthrough science. The post WWII environment following the Bush report (1945) made science and fundamental research the key source of major innovations. The need for research policy in support of basic and fundamental research was thus predicated on such utilitarian considerations. Currently fashionable policy concepts like 'research excellence' and 'frontier science' reflect this focus on the importance of basic research.

Our central assumption is that the balance between these 3 types of intervention is critical to the characterisation of the RTDI landscapes and need to be considered when using our scenarios to inform policy shaping. Using the three priorities described above, we can explore the scenarios with further granularity. One of the results of the characterisation of the RTDI landscape with this lens has been to highlight the importance of the innovation ecology in most scenarios but with very different orientations. Thus, we add another element to this lens based on this finding in the scenarios, and further articulate this part of the lens by probing the scenarios around four aspects: intellectual property (IP), standards, procurement policies and start-up ecology.

\footnotetext{
8 The early stages of Government involvement in science and technology have been associated in many developed countries to Defence, where Defence has remained the largest public spender in science and technology well after the end of the cold war. The enlargement of the sphere of Government missions is a major phenomenon that spans the last century - for example with communications, energy, health and environment - even if modes of interventions have changed over time (Foray et al. 2012). ${ }^{9}$ National Intellectual Property (IP) protection systems emerged in the 1840s, and the first international trade treaty was dedicated to industrial patenting.
} 


\section{Box 3 Types of research and innovation policy}

(1) Mission-oriented and challenge-oriented policies: define substantial problems that need to be addressed through science, technology and innovation. Often combine different tools and funding programmes to mobilise a broad base of research and innovation actors.

(2) Research and innovation ecosystem framework policies: shape the adequate institutional infrastructures (IPR, standards, and other regulatory interventions including tax regimes and public procurement practices).

(3) Support for fundamental and breakthrough science: We can differentiate two main avenues to provide such support: through the public funding of research in universities and their associated organisations, or through dedicate public research organisations (such as academies of science). We will also encounter different balances between 'core' and 'competitive' allocation of funds across countries.

\subsubsection{Lens 3: Modes of Europeanisation}

The third element of our policy lensing focuses on a key aspect of the research and innovation system for the European Research Area: the types and modes of Europeanisation. The dominant paradigm in international affairs is that countries/states are the basic unit of analysis and that the dominant mode through which countries relate to one another is 'inter-governmental cooperation'. In some cases, specific bodies are created in charge of a dedicated activity and countries delegate budgets and implementation to these bodies. Science and technology have been an important source of such creations, with two complementary models of intergovernmental cooperation: one driving to the creation of a performing entity (like CERN or numerous other large scientific instruments), the other driving to the creation of a funding agency (like the European Space Agency).

The creation of the EEC and then the EU has generated another development, by creating a 'federal layer' (e.g. Trechsel 2013), which in turn develops a "research and innovation policy" that is operated on the basis of the global budget delegated to Europe: Framework Programmes (and their specific sub-programmes) have been the outcome of this process. Recent years have witnessed additional developments:

a) Multiple new frameworks have been developed to support and foster European cooperation (ERA-Nets, JTI, Article 185...). Most of these new developments no longer take place at the 'orientation' layer but at the 'programming layer' (between agencies, and sometimes in combination with large performing organisations).

b) New European instruments have been created to share some orientation and programming functions (programming strategies, selection procedures, monitoring of results and effects) while funding remains within the hands of the respective national funders: EUREKA has been a front-runner in this movement.

These changes have been studied in depth in a European project (JOREP) (Lepori et al. 2014, Carvallero et al. 2020). Elaborating on Barré et al 2013, the focus group identified three modes of Europeanisation that would be of interest for European RTDI policy (see Box 4).

\section{Box 4: Modes of Europeanisation}

- Integration: this means the full delegation of decision making to a single European level entity with considerable autonomy and independence; strong and formalised institutionalisation, single budget 
- Coordination: this means that joint decision making is done by concerned entities (national or regional levels), based on a common understanding, guidelines and frameworks of reference; decisions apply to each entity which implement them on a voluntary engagement basis

- Juxtaposition: co-existence of entities acting in non-concerted way, in the ignorance of each other and / or in competition with each other

\section{Interpretation of the scenarios via the policy lenses}

The VERA scenarios, summarised in Box 1, represent different problem perceptions, different forms of dominant policy action, and different roles for the European institutions. Each scenario highlights profound differences in the political and social priorities that underpin the way in which problems are defined. Such differences result in varying understandings of the role of science and technology in society, and of the institutions involved in generating and applying new knowledge. These differences affect the way in policy is defined and implemented (its functional layers analysed through lens 1); policy objectives and priorities (lens 2), and the mode of Europeanisation (federalised, integrated, coordinated, or juxtaposed) (lens 3). Analysing the scenarios through these lenses highlights their policy implications.

This section draws some ramifications for current policy decisions of the lensed analysis conducted above, by building new narratives of interpretation of the futures described in each scenario. It presents the outcome of a "lensing workshop" followed by online interactions, where all eight members of the focus group came together to apply the lenses to each of the four scenarios, construct new narratives and highlight key policy relevant insights. In the remainder of this section, we focus on elaborating three dimensions that were made visible through the policy lensing approach and which represent actors or situations that are (in a way) present in all scenarios and are not (yet) considered at the adequate level in present policies. We highlight in bold some of the key points coming from the policy lensing and summarise them in section 4.4.

\subsection{Orienting, programming and performing policy}

\begin{tabular}{|c|c|c|c|c|c|}
\hline & $\begin{array}{l}\text { Scenario 1: Global } \\
\text { Markets }\end{array}$ & Scenario 2: Joint Action & $\begin{array}{l}\text { Scenario 3: Local is } \\
\text { Beautiful }\end{array}$ & $\begin{array}{l}\text { Scenario 4: Experts at } \\
\text { the Wheel }\end{array}$ \\
\hline \multicolumn{2}{|c|}{ Orientation Layer } & $\begin{array}{l}\text { No change in the way } \\
\text { member states } \\
\text { negotiate priorities - } \\
\text { focus on compromise } \\
\text { between national } \\
\text { priorities }\end{array}$ & $\begin{array}{l}\text { Radically changed } \\
\text { institutional process for } \\
\text { defining societal } \\
\text { challenges - central role } \\
\text { of European Parliament } \\
\text { (with processes to } \\
\text { interact with national } \\
\text { parliaments) }\end{array}$ & $\begin{array}{l}\text { Science and technology } \\
\text { policy is no longer an } \\
\text { object of negotiation - } \\
\text { ERA as driving } \\
\text { compromise making has } \\
\text { disappeared }\end{array}$ & $\begin{array}{l}\text { Crisis driven alignment } \\
\text { - no need for change at } \\
\text { the orientation layer }\end{array}$ \\
\hline \multirow{3}{*}{ 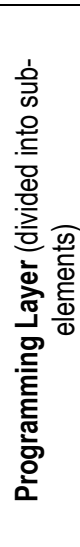 } & $\begin{array}{l}\text { Existence of an } \\
\text { encompassing } \\
\text { EU Framework } \\
\text { programme? }\end{array}$ & No & $\begin{array}{l}\text { Yes (with larger } \\
\text { resources than today) }\end{array}$ & No & No \\
\hline & $\begin{array}{l}\text { Sectoralisation of } \\
\text { research and } \\
\text { innovation } \\
\text { activities? }\end{array}$ & $\begin{array}{l}\text { Yes (amidst budget } \\
\text { constraints) }\end{array}$ & No & $\begin{array}{l}\text { Yes (but remains } \\
\text { marginal) }\end{array}$ & $\begin{array}{l}\text { Yes (with larger } \\
\text { resources) }\end{array}$ \\
\hline & $\begin{array}{l}\text { Main mode for EU } \\
\text { activities about } \\
\text { societal } \\
\text { challenges }\end{array}$ & $\begin{array}{l}\text { Public-private } \\
\text { partnerships with large } \\
\text { firms. Or remain orphan } \\
\text { and taken by civil } \\
\text { society organisations }\end{array}$ & $\begin{array}{l}\text { Large programme } \\
\text { similar to that of the } \\
\text { European Space } \\
\text { Agency approach } \\
\text { (downstream), key role }\end{array}$ & $\begin{array}{l}\text { None - only } \\
\text { intermediation activities } \\
\text { between local initiatives }\end{array}$ & $\begin{array}{l}\text { Multiple targeted } \\
\text { programmes mixing } \\
\text { technical and social } \\
\text { dimensions, focused on } \\
\text { experiments and central } \\
\text { role of citires, regions }\end{array}$ \\
\hline
\end{tabular}




\begin{tabular}{|c|c|c|c|c|c|}
\hline & & & $\begin{array}{l}\text { of 'real size' } \\
\text { experiments }\end{array}$ & & $\begin{array}{l}\text { and civil society } \\
\text { organisations }\end{array}$ \\
\hline & $\begin{array}{l}\text { Specific role of } \\
\text { communication } \\
\text { programmes? }\end{array}$ & $\begin{array}{l}\text { YES (mostly driven by } \\
\text { the circulation of goods) }\end{array}$ & $\begin{array}{l}\text { YES (through one } \\
\text { societal challenge: the } \\
\text { digital society) }\end{array}$ & $\begin{array}{l}\text { YES (mainly focused on } \\
\text { internet platforms) }\end{array}$ & $\begin{array}{l}\text { YES (driven by the need } \\
\text { to reduce the carbon } \\
\text { footprint) }\end{array}$ \\
\hline \multirow{2}{*}{ 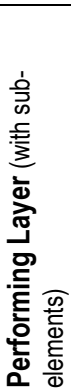 } & $\begin{array}{l}\text { Science and } \\
\text { Technology base } \\
\text { - respective role } \\
\text { of public research } \\
\text { organisations } \\
\text { (PRO) and } \\
\text { universities }\end{array}$ & $\begin{array}{l}\text { Focused on excellence. } \\
\text { Strong EU agencies for } \\
\text { breakthrough science } \\
\text { and technology. Strong } \\
\text { hierarchisation of } \\
\text { universities }\end{array}$ & $\begin{array}{l}\text { Key role of PRO as } \\
\text { solution integrators } \\
\text { (domain based EU } \\
\text { consolidation?) } \\
\text { Universities well off } \\
\text { (with spread of } \\
\text { activities/values) }\end{array}$ & $\begin{array}{l}\text { Not an EU priority } \\
\text { anymore (mostly } \\
\text { handled at the regional } \\
\text { level, key role of } \\
\text { universities) }\end{array}$ & $\begin{array}{l}\text { Similar role of PRO as } \\
\text { scenario } 2 \text {. Universities: } \\
\text { changing balance } \\
\text { between fields and } \\
\text { changing equilibrium } \\
\text { between excellence and } \\
\text { relevance }\end{array}$ \\
\hline & $\begin{array}{l}\text { Role of large } \\
\text { firms }\end{array}$ & $\begin{array}{l}\text { Central driving seat in } \\
\text { public-private } \\
\text { partnerships }\end{array}$ & $\begin{array}{l}\text { Key actor. Sharing with } \\
\text { civil society } \\
\text { organisations }\end{array}$ & $\begin{array}{l}\text { Not an issue. May be } \\
\text { critical in some local } \\
\text { environments }\end{array}$ & $\begin{array}{l}\text { Solution provider under } \\
\text { control of programmes }\end{array}$ \\
\hline
\end{tabular}

Table 2: Summary of the key elements of the four scenarios when the authors applied lens 1 (Functional Layers)

All scenarios anticipate shifts in the institutional architecture underpinning research and innovation policies. First, the importance of agencies will grow. Agencies are semi-autonomous public sector organisations that contract for a service with a government organisation. They are ad-hoc policy organisations with mainly programming and performing functions, and are designed specifically for the purpose for which they have been created. European agencies are already present in today's ERA strategies; the management of research programmes is being transferred to specialised agencies like the European Research Council Executive Agency and the Research Executive Agency. So far, their role has been instrumental, offering a way of performing specifically designed tasks without drawing on European Commission functionaries. Our scenarios describe a broader and differentiated view of agencies: they deal with specialized activities, but can also be a flexible tool to programme and perform policies at the local and regional levels accounting for the specific local context of application. The flexibility that can be afforded by national and regional agencies fits an environment where the orientation function is delivered at European level, but national and sub-national actors play key programming and performing functions. This will lead to a proliferation of smaller agencies with limited geographical scope with the EU helping in their coordination, further developing current programming instruments like ERA-Nets, Joint Programming Initiatives, and Article 185 initiatives.

We also anticipate the growth in the research arena of Civil Society Organisations (CSOs: foundations, NGOs, learned societies, university associations, etc.). CSOs are gaining influence within the policy processes and becoming an avenue of quasi-democratic representation. They are contributing to the orientation layer, proposing research directions and starting to contribute to the programming and even performance of research. CSOs will become a central set of actors to add to government institutions and private sector firms. Yet, our scenarios caution us that their functions are not predetermined and can evolve into different directions. Private philanthropic organisations can cover some of the gaps left by the reduction in public sector interventions (scenario 1), can form part of a broader collection of public and private bodies performing research (scenario 2) or can complement the research programming and performing roles of the public sector (scenario 4). CSOs are going to be engaged in more direct and operational ways than merely being the interlocutors in a diffuse "dialogue with society" and this will require changes in policy practice.

Finally, there is a programming aspect whose importance is common to all scenarios: all scenarios rely on extensive communication programmes, both in terms of physical transport and internet-based telecommunications. The transfer of physical goods is anticipated to be a central concern when the position of Europe in global supply networks is of paramount importance (scenario 1), whereas the notion of what can pass for an "efficient" mode of communication will rely more heavily on telecommunications and internet infrastructures in the remaining scenarios. 


\subsection{Policy objectives and priorities}

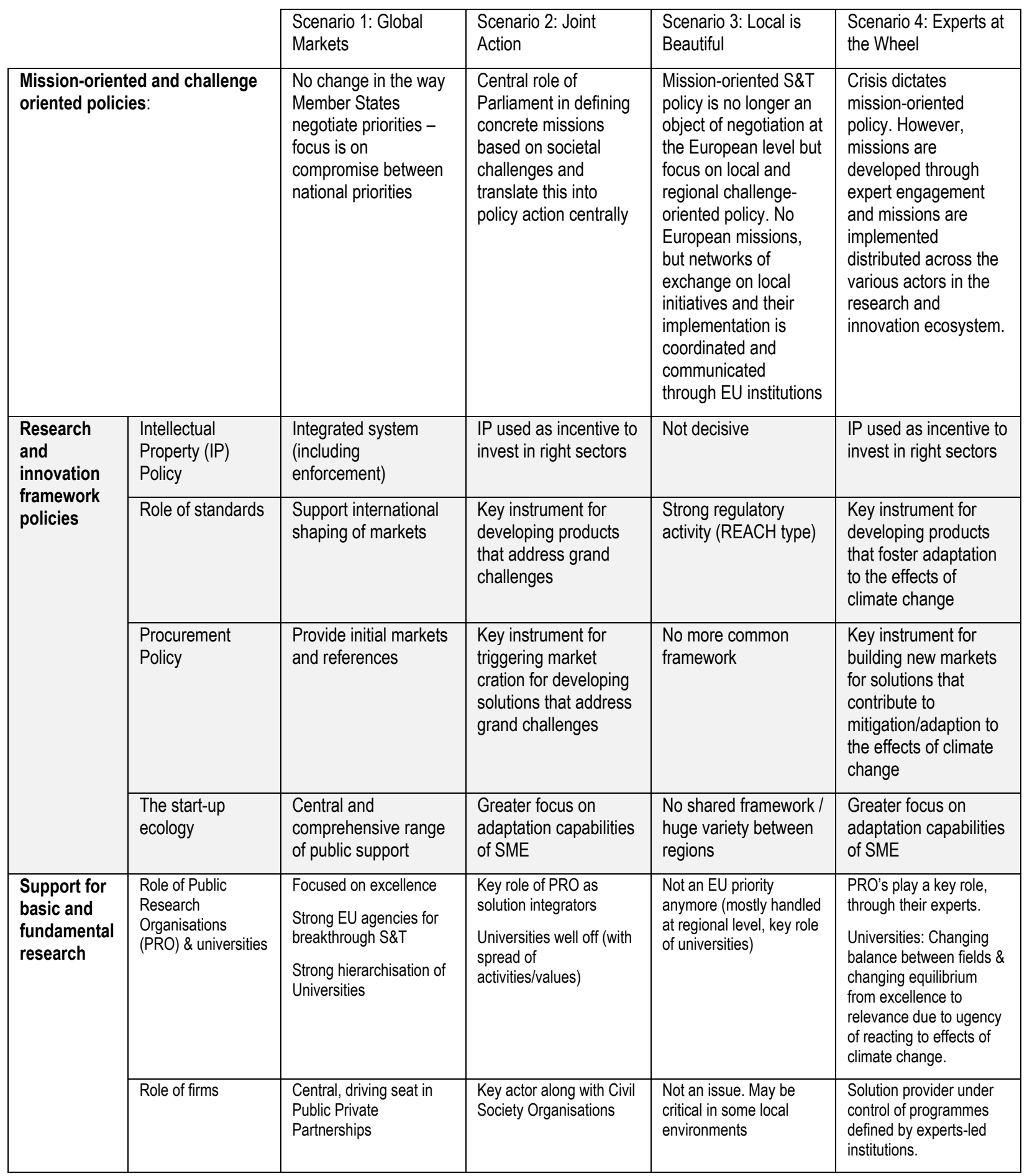

Table 3: Summary of the key elements of the four scenarios when the authors applied lens 2 (Policy Priorities)

One of the beliefs at the centre of many current policies is that the support of "excellent" basic and fundamental research should be the natural overriding objective of research policy. Clearly, it is difficult to argue against excellence. Yet, except for Scenario 1, the highly selective ethos of this approach is not present in any of the other scenarios. Instead, the concern with systemic effects and the application of research to address societal problems are 
the overriding concern in two of the scenarios. Therefore, the policy challenge we are currently facing is how to balance this pursuit of scientific excellence with the objectives that aim to make research organizations relevant to their local and regional contexts.

From a higher education perspective, many of the current practices (from funding mechanisms to the popularity of some ranking systems) are based on the implicit assumption that universities should aspire to excellence by improving their research capacity and outputs. Yet again, the role of universities varied across scenarios. This reflects the increasingly different functions that universities play in our societies. Scenario 3 for instance focuses on the local role of universities and their teaching function, while Scenario 4 sees a changing balance between excellence and relevance placing increasing importance on the latter. The scenarios draw our attention that the current focus on excellence and the consequent increased hierarchisation among universities is consistent with only one scenario (Scenario 1 Global Markets) but not with other more collaborative, challenge driven or locally-concerned policy settings.

Reconsidering our assumptions can modify the way in which we define policies, but there are specific policy areas that need attention, in all circumstances. In our scenario analysis, when an issue appeared in more than one scenario we consider it a warning sign of the existence of a policy problem that would be relevant in very different contexts. An important (and somewhat unexpected) outcome of this analysis is the importance that framework conditions (such as intellectual property rights, standards, regulatory activity focused on public procurement) and communication infrastructures have in most scenarios.

Framework conditions, as a policy priority, play an important role, but they do so in very different ways depending on the scenario. IPR, for instance, is prominent in scenario 1 as a condition for greater competitiveness of firms, and this scenario foresees the achievement of a full system covering 'one stop shop' for granting patents and a Europeanlevel enforcement system. In contrast, scenarios 2 and 4 are characterised by large public investments to address societal problems and here IP policies seek to ensure that the results of such research are publicly available. There are similar differences for standards: they serve the opening of markets for firms in scenario 1, while they are an instrument to reduce the environmental impact of goods and services in scenario 4. Similar differences in focus apply for regulations surrounding procurement policies.

Although these issues are often seen as purely technical matters, the scenarios alert us to their political nature. In other words, different research and innovation framework policies will be aligned with different political objectives.

Similarly, support for basic and fundamental research emerges as important in every scenario, but in different ways, with different levels of priority, and with different policy actors as the main responsible agents. Societal attitudes towards the various sciences (natural, technical, social) are far from homogenous, and the scenarios illustrate situations where scientific goals are considered secondary to other social objectives. In scenario 1, science is purely seen in an instrumental way rather than an activity that is valuable in itself. Scenario 3 presents an environment that is more concerned in harnessing current capabilities for welfare than in supporting scientific research. In all scenarios academic science is only one element among diversifying modes and actors of knowledge production and innovation. Therefore, the current policy challenge is to define how European policies can help in the experimentation and establishment of flexible but robust modes of distributed knowledge production.

In a sense the scenarios are schizophrenic with (a) excellence on the one hand and (b) solving societal problems on the other. While recognising there is a link between both and how this is organised, all organisations have to handle this balance (for example public research organisations)..$^{10}$

\footnotetext{
${ }^{10}$ This schizophrenia is visible in the recent resurgence of mission-oriented research. For example, in the French context, the funding programme Cutiver et Protéger Autrememnt funds basic research targeted at contribution to the "mission" of zero pesticide agriculture. Funding agencies and research organisations have to handle the tensions between open ended blue skies research and mission-orientation (Robinson and Mazzucato 2019). See https://www6.inrae.fr/cultiver-proteger-autrement_eng/ for details of the Zero pesticide programme.
} 


\subsection{Modes of Europeanisation}

\begin{tabular}{|l|c|c|c|c|}
\cline { 2 - 5 } \multicolumn{1}{c|}{} & $\begin{array}{l}\text { Scenario 1: Global } \\
\text { Markets }\end{array}$ & $\begin{array}{l}\text { Scenario 2: Joint } \\
\text { Action }\end{array}$ & $\begin{array}{l}\text { Scenario 3: Local is } \\
\text { Beautiful }\end{array}$ & $\begin{array}{l}\text { Scenario 4: Experts at } \\
\text { the Wheel }\end{array}$ \\
\hline INTEGRATION & no & YES & no & YES \\
\hline COORDINATION & YES & no & YES & YES \\
\hline JUXTAPOSITION & no & no & YES & no \\
\hline
\end{tabular}

Table 4: Summary of the key elements of the four scenarios when the authors applied lens 3 (Modes of Europeanisation)

Often, in policy discussions, the institutional architecture of the EU is taken for granted. It is an implicit assumption of many European policies, that a "common area" will, and should, deliver a single and integrated European research and innovation system. This, the argument goes, is a precondition to increase the efficiency and effectiveness of research and innovation investments. Free mobility of resources in a single integrated system is the best way to allocate resources, as in any other "market". In many of our scenarios, however, system integration was replaced by different forms of connectedness, and the role of the EU and its institutions differed across scenarios. In Scenario 1 (Global Markets) public sector institutions are generally weak and fragmented, national authorities have struggled to retain a degree of influence over the political process and of control over economic resources, and the EU institutions have seen their remit limited to setting regulatory structures and other framework conditions, playing a coordination role. Scenarios 2 (Joint Action) and 4 (Experts at the Wheel) present a very different situation. In them, the EU and its institutions have become a key player, growing in size and legitimacy, and taking over responsibilities that currently are the remit of national and regional authorities. Yet, the political configuration of the EU institutions will depend on the political context. In scenario 2, European societies come together to deal with policy problems whose solution exceeds the capacity of any single State. This transfer of authority to supranational organisations (integration) comes accompanied by the development of instruments of democratic oversight at European level: a strong European Parliament provides the source of democratic legitimacy. In scenario 4 the EU and its institutions are also playing a key role but there is a focus on a single set of problems leading to more narrowly focused European institutions playing coordination roles or establishing supranational authorities (integration) for very specific policy domains. Finally, scenario 3 (Local is Beautiful) is dominated by local and regional interests, and the role of the EU institutions is limited to that of a facilitator, supporting policy learning and information sharing across policy and scientific communities. As the focus here is on local conditions and the development of capacities that can deal with the local and regional qualities of more general social challenges, this scenario is not consistent with the full delegation of decision making to a single European level entity with considerable autonomy and independence (integration), and will instead co-exist with some institutional juxtaposition in which entities involved in research and innovation operate in a non-concerted way.

The variety of institutional landscapes that emerge in different scenarios implies that the evolution of the ERA, and of the role of the EU in an evolving European research and innovation system can still take widely divergent paths associated with the development of different European governance structures. The balance among the policy levels is subject to big uncertainties: The regional level is, together with the local, the central locus of science, technology, and innovation policy in scenario 3, and it is also important for the experimentation and eventual deployment of innovations in scenario 4. European institutions are dominant in scenario 2 and national governments have retained a degree of influence and relevance against the general retrenchment of the State in scenario 1. Therefore, we cannot assume that there is a natural evolution towards European-wide institutions and that policy measures supporting institutional integration at European level will receive the necessary political support. There is, instead, a choice among different institutional architectures and this choice is not neutral in relation to political objectives. For instance, a strong role for European institutions fits with a scenario in which national authorities have agreed to pursue a variety of societal goals requiring international coordination, but cannot be sustained by a scenario characterised by tight and enduring budgetary constraints in the public sector and a focus on private firms as the engine of competitiveness and economic growth. 


\subsection{Summarising the three lenses}

For lens 1, and reflecting on some of the insights made visible in Table 2, we can see that the Orientation Layer, which is taken for granted in the European Commission Framework Programme, is only present in one example (Scenario 1). This has profound ramifications for the organisation, structuring and implementation of research and innovation policy across the other three scenarios. Note that in scenario 3, the role of the European Parliament is central in defining societal challenges that guide (but do not direct) European wide policy. We can also see a crossscenario role for communication infrastructures, though the shape and balance varies. The way in which communication infrastructures drive and shape innovation systems manifests in different was in the scenarios. At the performance layer, we see a difference in who are the central key involved players. For example, in scenario 1, firms play a leading role, scenario 2 they are important but public research organisations and civil society organisations play an equally important role, and in scenario 3 where they play less of a central role.

Regarding lens 2, and reflecting on some of the insights made visible in Table 3, we can see that mission oriented and challenge-oriented policies manifest differently in each scenario. In scenario 1, there is little or no missionoriented policy. Scenario 2 sees a strong coordination and directing role for the European Parliament, which select societal challenges and facilitates their translation into "missions". In contrast, European-wide mission-oriented policy is absent in scenario 3, where the focus is on regional and local "missions" focused on context-specific challenges. Scenario 3 sees European institutions as communicators and capacity builders through communication infrastructure and twinning of regions for sharing lessons learned and building capacity. Scenario 4 sees another manifestation of mission-oriented policy construction and implementation. In Scenario 4, a scenario of crisis, experts take the lead and develop missions that then guide research and innovation ecosystems. In this case, mission implementation is distributed widely across many actors, whilst the definition of policy is centralised (as opposed to scenario 3 where missions are defined in a decentralised way based on local or regional specific challenges. Regarding research and innovation framework policies, we do not see much difference in framework policies (except in scenario 3 where there are no European-wide frameworks), but their use is radically different. For Scenario 1 they are targeted at increasing competitiveness in global markets. For scenario 2 they are used to create new markets inline with societal challenges, where similarly scenario 4 show the same motivation but focused on adaptation to the effects of climate change (providing more urgency to create markets).

For Lens 3, reflecting on some of the insights made visible in Table 4, we can see that two scenarios have strong integration approach to Europeanisation. For scenario 4, this relates to the need for global /European-wide adaptation to the effects of climate change (adapt to floods, unbalanced climate effecting food security etc.). Implementation is done locally (and coordinated through European Institutions) but strategies are centrally defined. For scenario 2 , infrastructure plays a large role, it gives a central role to democratic representatives and requires harmonisation by national and EU parliaments., therefore a need for strong integration. Scenario 3 is a case of juxtaposition, where policies and implementation is done locally, but knowledge of such activities is shared (and maintained) through European communication institutions. 


\section{Conclusion}

We began this article pointing out that strategic intelligence, such as foresight, can provide essential insights to inform and direct policy. As futures analysts looking to inform or shape policy, we need to translate the outcomes foresight exercises into policy language, then this intelligence can play a useful role in decision making. Lenses correspond to the way policies are framed. We use the term lensing because the approach translates scenario "worlds" in terms of perspectives from a policy shaper standpoint, but also alters and adds to the scenario texts: it requires further elaboration and interpretation of the scenario world. These eventual narratives are framed in the language of policy makers, and the lenses help the policy-lensing analyst do this. This hybrid role of translation and further scenario articulation means the approach sits between the world of the futures analyst and the policy shaper, combining the perspectives and assessment processes from both worlds.

In this paper, we have developed three policy lenses related to specific policy challenges for driving and directing the European research and innovation system. One could use different policy lenses to translate strategic intelligence from foresight or technology assessment for policy questions, for example regarding Justice - to do so would require different translation rationales (different lenses). For policy lensing tailoring is important because in each sector, domain or field there are different mechanisms to build policy and one needs to understand and work with different policy categories. ${ }^{11}$

In the experiment described in this article, the policy-lensing approach adds to the scenario-building process (the construction of consistent scenario-worlds per se) by interpreting and fleshing out these worlds to inform policy decisions today. This means that the analyst undertaking policy lensing plays a hybrid role - she retains the tools and skill sets of a futures analyst whilst placing herself in the position of a policy shaper. By doing so, the analyst connects the scenarios to the present situation, allowing for the assessment of policy options. Without policy lensing, the interpretation step for scenarios requires substantial work, usually left to the user of this intelligence - the policy shaper. By taking a first step in producing a systematic approach to this interpretative step via lenses, we as futures analysts help produce usable future-oriented strategic intelligence.

Reflecting on the specific scenario exercise described in this paper, our specific interest in developing policy lenses was for the European research and innovation landscape and aspects of Europeanisation (cf. European Research Area). Policy lensing brings to the fore different problem perceptions, different forms of dominant policy action, and different roles for the European institutions involved. Our scenarios highlight profound differences in the political and social priorities that underpin the way in which problems are defined. Such differences result in varying understandings of the role of science and technology in society, and of the institutions involved in generating and applying new knowledge. The scenario and the policy lensing have helped us question our current assumptions on the context, drivers and objectives of research policies.

The scenarios of European research and innovation systems show that the landscape of actors and institutions of European research and innovation will change in the coming decade, and quite likely it will become more complex. Policymakers today need to anticipate such changes and to reflect about the assumptions underlying present-day research and innovation policies. Dimensions, concepts and approaches currently taken for granted can become irrelevant. Scenarios, like those developed in the VERA project, help us anticipate how the institutional context under which European research and innovation policy will be defined and implemented - within two decades the situation may be substantially different from the situation we are experiencing today. Yet, to a large extent, our current decisions will shape such context; what we are doing today opens and closes options for the future.

In this regard, a major value-added of the policy-lensing approach lies in the opening-up of policy spaces, of choices and their potential consequences in the different political and societal contexts as defined by the scenarios.

11 Of course, other lenses might be developed for exploring scenarios from a policy shaper perspective other than that relating to research and innovation (for example in national or international sustainability policies, energy, transport etc.). What is key, is that the lenses are constructed in a systematic and transparent way. 
It could be argued that the policy lenses do not generate more than an extension of the scenario and that, therefore, they could be part of the scenario itself. Yet, there is a clear difference between the construction of plausible and coherent scenarios, and their application to current policy analysis. When the policy interpretation of strategic intelligence is kept separate from it's production, as was the case for the VERA scenarios, policy lensing offers a structured way to do this interpretation. The lensing does not "extend" the scenarios, but uses them as a tool in policy definition, by drawing on conceptual frameworks and extant theory to help us derive policy interpretations and conclusions from the scenarios. We propose that there are two specific contributions of policy lensing as an independent activity after the development of scenarios:

- Deriving policy implications from future-oriented strategic intelligence. Through policy lensing we analyse the policy implications of the strategic intelligence such as scenarios with respect to relevant operational policy categories. For instance, interpreting the implications of the VERA scenarios for the three policy layers (orientation, programming and performance) bridges from the general policy factors to the specific tasks that need to be addressed in the policy process. This is something that cannot be done in the collective process of scenario building as it is not accessible to the non-policy participants. In short, it develops the scenario outputs into usable intelligence for policy action.

- Making explicit the differing normative assumptions lying behind the different scenarios and their use in policy design. Analyzing the scenarios vis-a-vis policy categories and goals, underlines the differences among these goals and helps make explicit, and contestable, the "normativity" that lies behind the scenarios. ${ }^{12}$ Often, in the construction of policy scenarios, participants in the process construct some of the scenarios as desirable ones and others as non-desirable. Although, such normative considerations in the process of scenario construction are not present in the description of the scenarios themselves, but are likely to affect the way in which they are interpreted. It is therefore important that such normative considerations are made explicit, and it is through systematic policy lensing that different normative approaches can be explicitly recognised and their policy implications systematically considered.

Both aspects are well in line with the notion of adaptive Foresight (Eriksson and Weber 2008, Minkkinen 2019) which suggests a special sense making phase for each actor group and policy.

The experiment presented here should be seen as a first step in the development of a robust approach to policylensing. The make-up of the policy-lensing focus group is key, and further reflection on the composition and the expertise needed is required. In this experiment, the initiators of the policy lensing exercise were also the members of the focus group. One approach to future policy lensing would be to add an expertise scoping step - is there sufficient expertise to undertake robust policy lensing? Or are further group members needed? Moreover, would the lenses themselves co-evolve with this additional expertise? Or should the lens development and the "lensing" be distinct and separate activities? These are questions that should be part of the work of further developing the policy lensing technique. A further point, whilst some lenses will necessarily be bespoke to a particular context, one can imagine some lenses may have broader application - for example, Lens 1 in our approach: the functional layers of policy.

We have presented our experiment with the policy lensing approach and have shown the logic and rationales for constructing and using each lens. For broader generalisation of this technique, more experimentation is needed. Through such further experimentation, best practices can be developed, particularly with regards to the constituent expertise needed within the policy lensing focus group. In this paper, we hope to have provided an insight into this policy lensing approach and its relevance so that it can be taken further, and we offer it as a potential next step to further enable the uptake of future-oriented strategic intelligence into policy relevant intelligence.

\footnotetext{
12 This of course is different for the situation of "normative scenarios", which keep normative positions central in the scenario process (see Section 1 regarding normative scenarios).
} 


\section{References}

Andersen, A. D., \& Andersen, P. D. (2014). Innovation system foresight. Technological Forecasting and Social Change, 88, 276286.

Barré, R., Henriques, L., Pontikakis, D., and Weber, K. M. (2013). Measuring the integration and coordination dynamics of the European Research Area. Science and Public Policy, 40(2), 187-205.

Boe-Lillegraven, S., \& Monterde, S. (2015). Exploring the cognitive value of technology foresight: The case of the Cisco Technology Radar. Technological Forecasting and Social Change, 101, 62-82.

Bootz, J. P. (2010). Strategic foresight and organizational learning: A survey and critical analysis. Technological forecasting and social change, 77(9), 1588-1594.

Borras, S. (2004). System of innovation theory and the European Union. In: Science and Public Policy, vol. 31, no. 6, pp. 425433.

Borrás, S., \& Edler, J. (2020). The roles of the state in the governance of socio-technical systems' transformation. Research Policy, 49(5), 103971.

Bourgeois, R., Penunia, E., Bisht, S. and Boruk, D. (2017). Foresight for all: Co-elaborative scenario building and empowerment. Technological Forecasting and Social Change, 124, 178-188.

Bowman, G., \& MacKay, R. B. (2020). Scenario planning as strategic activity: A practice-orientated approach. Futures \& Foresight Science, 2(3-4), e32.

Cagnin, C., Keenan, M., Johnston, R., Scapolo, F., and Barré, R. (Eds.). (2008). Future-oriented technology analysis: strategic intelligence for an innovative economy. Springer Science \& Business Media.

Cavallaro, M., \& Lepori, B. (2020). Institutional barriers to participation in EU framework programs: contrasting the Swiss and UK cases. Scientometrics, 1-18.

Chaminade, C. \& Edquist, C. (2010). Rationales for public policy intervention in the innovation process: A systems of innovation approach. In: Smits, R.; Kuhlmann, S.; Shapira, P. (eds.): The Theory and Practice of Innovation Policy. An International Research Handbook, Cheltenham, UK (Edward Elgar), 95-114.

Curry, A. \& Hodgson, A. (2008): Seeing in Multiple Horizons: Connecting Futures to Strategy. In: Jour-nal of Futures Studies, 13 (1), $1-20$.

Da Costa, O., Warnke, P., Cagnin, C. andScapolo, F. (2008). The impact of foresight on policy-making: insights from the FORLEARN mutual learning process. Technology Analysis \& Strategic Management, 20(3), 369-387.

Delemarle, A., \& Larédo, P. (2014). Chapter 8. Governing radical change through the emergence of a governance arrangement. The Governance of Socio-Technical Systems: Explaining Change, 159.

Dönitz, E., Shala, E., Leimbach, T., Bierwisch, A., Grigoleit, S. and Klerx, J. (2013): D4.4 Catalogue of threat Scenarios. Deliverable submitted in September, 2013 (M21) in fulfilment of the requirements of the FP7 project "ETTIS - European security trends and threats in society". Available from: http://ettis-project.eu/wp-content/uploads/2012/03/D4_4.pdf [24/10/2013]

Edler, J.; Kuhlmann, S., and Behrens, M. (eds.) (2003). Changing Governance of Research and Technology Policy - the European Research Area. Cheltenham: E. Elgar.

EFFLA (2014) Strategic Intelligence Methodology. POLICY BRIEF 13 European Forum on Forward Looking Activities. European Commission.

Elsawah, S., Hamilton, S., Jakeman, T., Rothman, D., Schweizer, V., Trutnevyte, E., ... and Guivarch, C. (2020). Scenario processes for socio-environmental systems analysis of futures: A review of recent efforts and a salient research agenda for supporting decision making. Science of the Total Environment, 138393.

Eriksson, E.A. \& Weber, K.M. (2008): Adaptive Foresight: Navigating the complex land-scape of policy strategies. In: Technological Forecasting and Social Change, 75 (4), pp. 462-482.

Foray, D., Mowery, D. C. and Nelson, R. R. (2012). Public R\&D; and social challenges: What lessons from mission R\&D; programs?. Research policy, 41, 1697-1702. 
Frau, I. (2020) Foresight in Public Policymaking: An Exploration of Process Practices. PhD dissertation. University of Cambridge. Available online at: https://www.repository.cam.ac.uk/bitstream/handle/1810/307558/Final\%2020200630_1.pdf?sequence=5

Geels, F. W. (2002). Technological transitions as evolutionary reconfiguration processes: a multi-level perspective and a casestudy. Research policy, 31(8), 1257-1274.

Georghiou, L., J.C. Harper; M. Keenan, I. Miles and R. Popper (eds.) (2008). The Handbook of Technology Foresight: Concepts and Practice, Edward Elgar Publishing Ltd., Cheltenham, UK; Northampton, MA, USA, 2008.

Glick, M. B., Chermack, T. J., Luckel, H., \& Gauck, B. Q. (2012). Effects of scenario planning on participant mental models. European Journal of Training and Development, Vol. 36 No. 5, pp. 488-507. https://doi.org/10.1108/03090591211232066

Godet, M. (2001): Creating Futures. Scenario Planning as Strategic Management Tool, London: Economica.

Haeffner, M., Leone, D., Coons, L., and Chermack, T. (2012). The effects of scenario planning on participant perceptions of learning organization characteristics. Human Resource Development Quarterly, 23(4), 519-542.

Havas, A., \& Weber, M. (2017). The role of foresight in shaping the next production revolution. The Next Production Revolution: Implications for Governments and Business, Paris: OECD, 299-324.

Hooghe, L., \& Marks, G. (2001). Multi-level governance and European integration. Rowman \& Littlefield.

Köhler, J., Geels, F. W., Kern, F., Markard, J., Onsongo, E., Wieczorek, A., ... and Wells, P. (2019). An agenda for sustainability transitions research: State of the art and future directions. Environmental Innovation and Societal Transitions, 31, 1-32.

Konrad, K., \& Böhle, K. (2019). Socio-technical futures and the governance of innovation processes-An introduction to the special issue. Futures, 109, 101-107.

Kuhlmann, S. (2001). Future governance of innovation policy in Europe-three scenarios. Research policy, 30(6), 953-976.

Kuhlmann, S., \& Edler, J. (2003). Scenarios of technology and innovation policies in Europe: investigating future governance. Technological Forecasting and Social Change, 70(7), 619-637.

Lepori, B., Reale, E., and Larédo, P. (2014). Logics of integration and actors' strategies in European joint programs. Research Policy, 43(2), 391-402.

Lepori, Benedetto, Peter Van den Besselaar, Michael Dinges, Bianca Potì, Emanuela Reale, Stig Slipersæter, Jean Thèves, and Barend Van der Meulen. "Comparing the evolution of national research policies: what patterns of change?." Science and Public Policy 34, no. 6 (2007): 372-388.

Majone, G. (2009). Dilemmas of European integration: the ambiguities and pitfalls of integration by stealth. OUP Catalogue.

Mazzucato, M. (2018) Mission-Oriented Research \& Innovation in the European Union: A problem-solving approach to fuel innovation-led growth European Commission. ISBN 978-92-79-79918-1 doi:10.2777/36546

Menzies, M., \& Middleton, L. (2020). Using Scenarios in Public Policy. Policy Quarterly, 16(2).

Miles, I., Meissner, D., Vonortas, N. S., and Carayannis, E. (2017). Technology foresight in transition. Technological Forecasting and Social Change. Volume 119, June 2017, Pages 211-218

Miller, R. (2007): Futures literacy: A hybrid strategic scenario method. In: Futures, 39 (4), pp. 341-362.

Miller, R., \& Sandford, R. (2019). Futures Literacy: The Capacity to Diversify Conscious Human Anticipation. A Handbook of Anticipation. Holland: Springer.

Minkkinen, M., Auffermann, B., and Ahokas, I. (2019). Six foresight frames: Classifying policy foresight processes in foresight systems according to perceived unpredictability and pursued change. Technological Forecasting and Social Change, 149, 119753.

Minkkinen, M. (2019). The anatomy of plausible futures in policy processes: Comparing the cases of data protection and comprehensive security. Technological Forecasting and Social Change, 143, 172-180.

Popper, R. (2008): Foresight Methodology. In: Georghiou, L./Harper, J.C./Keenan, M./Miles, I./Popper, R. (Eds.): The Handbook of Technology Foresight: Concepts and Practice. PRIME Series on Research and Innovation Policy. Edward Elgar, Cheltenham, UK/Northampton, MA,USA, 44-88. 
Rhisiart, M., Miller, R., and Brooks, S. (2015). Learning to use the future: developing foresight capabilities through scenario processes. Technological Forecasting and Social Change, 101, 124-133.

Ringland, G. (2002): Scenarios in public policy, Chichester: John Wiley \& Sons.

Rip, A. (1994). The republic of science in the 1990s. Higher Education, 28(1), 3-23.

Robinson, D. K. R. (2009). Co-evolutionary scenarios: An application to prospecting futures of the responsible development of nanotechnology. Technological Forecasting and Social Change, 76(9), 1222-1239.

Robinson, D.K.R., \& Mazzucato, M. (2019). The evolution of mission-oriented policies: Exploring changing market creating policies in the US and European space sector. Research Policy, 48(4), 936-948.

Robinson, D. K. R., Lagnau, A., and Boon, W. P. (2019). Innovation pathways in additive manufacturing: Methods for tracing emerging and branching paths from rapid prototyping to alternative applications. Technological Forecasting and Social Change, 146, 733-750.

Rotolo, D., Rafols, I., Hopkins, M. M., and Leydesdorff, L. (2017). Strategic intelligence on emerging technologies: Scientometric overlay mapping. Journal of the Association for Information Science and Technology, 68(1), 214-233.

Sarewitz, D., \& Pielke Jr, R. (1999). Prediction in science and policy. Technology in Society, 21(2), 121-133.

Saritas, O. (2013). Systemic foresight methodology. In Science, Technology and Innovation Policy for the Future (pp. 83-117). Springer Berlin Heidelberg.

Schirrmeister, E., \& Warnke, P. (2013). Envisioning structural transformation-lessons from a foresight project on the future of innovation. Technological Forecasting and Social Change, 80(3), 453-466.

Schoen, A., Könnölä, T., Warnke, P., Barré, R. and Kuhlmann, S. (2011). Tailoring Foresight to field specificities. Futures, 2011, 3, 232-242.

Sharpe, B., Hodgson, A., Leicester, G., Lyon, A., and Fazey, I. (2016). Three horizons: a pathways practice for transformation. Ecology and Society, 21(2).

Smits, R., \& Kuhlmann, S. (2004). The rise of systemic instruments in innovation policy. International journal of foresight and innovation policy, 1(1-2), 4-32.

Teufel, B., Lorenz, E., Schirrmeister, E., Daimer, S., Laredo, P., Schoen, A., Robinson, D. K. R. and Loikkanen, T. (2014) ERA Scenario Report. VERA Deliverable D3.1. Project Number 290705. 7th Framework programme. SSH.2011.7.1-1 (http://eravisions.eu/)

Trechsel, A. H. (ed.) (2013). Towards a Federal Europe. Journal of European Public Policy Special Issues as Books. Routledge van Asselt, M.B.A., van't Klooster, S.A., van Notten, P.W.F., Smits, L.A. (2010): Foresight in action : Developing policy-oriented scenarios: Earthscan Publ. Ltd., London u.a.

van der Heijden, K. (2005): Scenarios. The art of strategic conversation, Second, Chichester: John Wiley \& Sons.

van Notten, P.W.F., Rotmans, J., van Asselt, M.B.A. and Rothman, D.S. (2003): An updated scenario typology. In: Futures, 35 (5), pp. 423-443.

Van Vliet, M., Kok, K., Veldkamp, A. and Sarkki, S. (2012): Structure in creativity: An exploratory study to analyse the effects of structuring tools on scenario workshop results. In: Futures, Vol. 44, pp. 746-760.

Van Woensel, L. (2019). A Bias Radar for Responsible Policy-Making: Foresight-Based Scientific Advice. Springer Nature.

Weber, K. M., \& Schaper-Rinkel, P. (2017). European sectoral innovation foresight: Identifying emerging cross-sectoral patterns and policy issues. Technological forecasting and social change, 115, 240-250.

Weber, K. M., Gudowsky, N., Aichholzer, G. (2019). Foresight and technology assessment for the Austrian parliament-Finding new ways of debating the future of industry 4.0. Futures, 109, 240-251. 
Version 30th March 2021 - pre-submission 